\title{
Inventory Management Practices and Related Challenges of Government Institutions, A Survey Study Conducted on the Wolaita Sodo University, Southern Ethiopia
}

\author{
Fanuel Bosha Bonga \\ Lecturer, Department of Management, Woalita Sodo University, Southern Ethiopia \\ P.o.box: 138 Wolita Sodo \\ Lidetu Alemu Anjulo (Assistant Professor) \\ Lecturer, Department of Management, Woalita Sodo University, Southern Ethiopia \\ P.o.box: 138 Wolita Sodo
}

\begin{abstract}
One of the most important parts of materials management is inventory management and which has been observed that there is lack of effective and efficient inventory management practices in some institutions in Ethiopia as a result most institutions are not successful. The purpose of this study was to assess the existing inventory management practices and internal controls of a Wolita Sodo University in Ethiopia. The study employed interview questions and administered questionnaire and observation to collect primary data from the administrative staff of the university. Purposive sampling approach was employed to identify sixteen employees directly involved in inventory management operations. The quantitative data was analyzed with the aid of Statistical Package for Social Sciences (SPSS) version 20. The study revealed that the university has poor inventory management practices and for this end it is better if the university uses scientific methods of managing inventories and should modernize and computerize the inventory management and recording procedures in order to meet customer demands and for smooth functioning of the institution. Moreover, it was revealed that, the company was faced with serious long lead time challenges due to bureaucratic procedures in ordering parts leading to cancellation of purchase orders and losing customers.
\end{abstract}

Keywords: Inventory, Inventory management, lead time, internal control

DOI: $10.7176 /$ IEL/9-4-01

Publication date:May $31^{\text {st }} 2019$

\section{INTRODUCTION}

\subsection{Background of Study}

As cited in Fianko A et al, (2016) Inventory management is a complex aspect of Supply Chain Management that is frequently discussed and debated due to the fact that it has a high impact on customer satisfaction as well as financial performance. Inventory management has become necessary in modern businesses in order to achieve excellent customer service, Cost reduction, Enhancing supply chain competitiveness and performance, Gaining market share, growth and expansion of businesses as well as Profitability (De Leeuw et al., 2011; Rao andRao, 2009). Stevenson (2009) on the other hand indicated that, Poor inventory management hampers operations, diminishes customer satisfaction and increases operating costs. Inventory management is primarily about specifying the size and placement of stocked goods. In their study, Stock et al.(2001) observed that corporate profitability can be improved by increasing sales volume or cutting down inventory costs. The inventory investment for most businesses takes up a big percentage of the total budget, yet inventory control is one of the most neglected management areas in most firms. Many firms have excess amount of inventory due to poor inventory management practices. Jessop and Morrison (1994) stated that, keeping Inventory value at the lowest practicable level is to economize the use of working capital and to minimize the cost of storage. However, there is always the challenge of managing inventory to balance supply with demand in order to satisfy customers. Firms would ideally want to have enough inventories to satisfy the demands of its customers, and ensure no lost sales due to inventory stock outs. At the same time they want to avoid too much inventory on hand because of the cost of carrying inventory; the trade-off is always difficult to manage. Enough but not too much is the ultimate objective (Coyle et al., 2003). In actual practice many companies suffer from lower customer service, high costs and excess stocks than are necessary. Delays in lead time due to variability in demand of products have resulted in substantial stock outs and backorders thereby causing the inability of suppliers to satisfy customer needs.

Inventory management is vital for the successful operation of most organizations due to the cost inventory represents. Effective management of inventory is a major concern for firms in all industries (Mentzeret al., 2007). There is therefore the need for firms to effectively and efficiently manage their inventories. There are two main concerns about inventory management. First, inventory management concerns the level of customer service 
(order fulfillment), that is, to have the right goods in sufficient quantities, at the right place and at the right time. Another concern is the cost of ordering and carrying inventories (Stevenson, 2009; Coyle et al.,2003). Inventory management could be defined as the policies and procedures which systematically determine and regulate which items to order, when to order, what should be kept in stock and what quantities of them are stocked(Toomey, 2000; Stevenson, 2009) Hence, the overall objective of inventory management is to attain satisfactory level of customer service by keeping inventory costs within reasonable bounds, amplify corporate profitability, and to minimize inventory investment(Stock and Lambert, 2001; Investopedia,2012).

\subsection{Statements of the problem}

According to (Stem and Ei-Ansary,1992,p,150.) have found that lack of strategic significance of inventory management had effect that either negative or positive effect on the factory. Inventory management in manufacturing is the main problems of many organizations. The inventory management practices that are implemented by organizations are associated with various advantages and disadvantages. As Noor (2006) argue that it is critical to evaluate how an organization is impacted by various inventory management techniques in order to advise the most suitable technique. In the same line of argument, Githendu, Nyamwange and Akelo (2008) provide that most of the firms face operational and financial difficulties owing to selecting inappropriate inventory management technique or lack of adequate information as regards how to implement effectively such techniques.

The failure to choose appropriate inventory management practices or integrating relevant information in the process of implementing these practices in the most effective way usually lead to poor performance of organizations. Bicheno (1996) accentuates that the growth of organizations is mainly dependent on the consistent positive performances of the organizations. A number of researches have established that fast moving consumer goods are very volatile and need to be replaced quickly; on the other hand, durable consumer goods, such as an automobile model, can become outdated thus representing a high risk to the manufacturer (PwC, 2016; OECD, 2012). Furthermore, as informed by Deloitte (2014), more than two-hundred million or twenty percent of Africans are aged between fifteen and twenty-four years, and that the demographic is expected to grow to threehundred and twenty-one million by 2030. This means that there will be an increase in demand for consumer goods because the middle class, which highly depends on consumer goods, is currently joined by a large percentage of young Africans. According to Global Edge (2016), the top industry in Kenya is that of Small-scale consumer goods, which majorly focus on plastic, batteries, furniture, textiles and clothing among other products, such as soap, cigarettes and flour. Other small-scale consumer goods produced in Kenya include horticulture, agricultural products and oil refining. This indicates that Kenya's economy highly depends on consumer goods manufacturing firms. These factors emphasize why it is crucial to choose the consumer goods manufacturing firms as the study ground.

The inventory investment for most businesses takes up a big percentage of the total budget, yet inventory control is one of the most neglected management areas in most firms. Many firms have excess amount of inventory due to poor inventory management practices. Jessop and Morrison (1994) stated that, keeping Inventory value at the lowest practicable level is to economize the use of working capital and to minimize the cost of storage. However, there is always the challenge of managing inventory to balance supply with demand in order to satisfy customers. Firms would ideally want to have enough inventories to satisfy the demands of its customers, and ensure no lost sales due to inventory stock outs. At the same time they want to avoid too much inventory on hand because of the cost of carrying inventory; the trade-off is always difficult to manage. Enough but not too much is the ultimate objective (Coyle et al., 2003). In actual practice many companies suffer from lower customer service, high costs and excess stocks than are necessary. Delays in lead time due to variability in demand of products have resulted in substantial stock outs and backorders thereby causing the inability of suppliers to satisfy customer needs.

\subsection{Research questions}

This study was proposed to provide answer to the following basic questions.

1. What are the inventory management techniques used by the institution?

2. What are the major challenges that the university faced on managing inventories?

3. What are the steps taken to remove unnecessary items from the institution?

4. Is the university has item maintainer procedures?

5. What is the length lead time for items?

6. For how long inventory counting take place per a year?

7. What are the costs that the university incurred in managing inventories? 


\subsection{Objective of the study}

\subsubsection{General objective}

Inventory Management Practices and Related Challenges of Government Institutions, A survey study conducted on the Wolaita Sodo University, Southern Ethiopia

\subsubsection{Specific objectives}

The following were the specific objectives of the study;-

1. To know the inventory management techniques used by the institution

2. To assess the major challenges that the university faced on managing inventories

3. To address the steps taken to remove unnecessary items from the institution

4. To assure that the university has item maintenance procedures

5. To know the length of lead time for items

6. To know long inventory counting take place per a year

7. To assess costs that the university incurred in managing inventories

\section{LITERATURE REVIEW}

\subsection{Inventory management and warehousing}

The explanation of inventory varies across scholars but they all have the same meaning. Inventory is basically, the raw materials, work-in-process goods, component parts and completely finished goods that are considered to be portion of a business asset and are ready or will be ready for sale. Inventory represents the most important assets that most businesses possess, because the turnover of inventory represents one of the primary sources of revenue generation and subsequent earnings for the companies' shareholders (Investopedia, 2012; Zagena, 2009). Also, Chase et al.(2004)inventory is all the tangible material assets used in an organization except fixed assets. Inventories can be classified according to the purpose they serve. These include: transit inventory, buffer inventory, anticipated inventory, decoupling inventory and cycle inventory (Stevenson, 2009). Every organization holds some things in stock. Stock can be a nuisance, a necessity, or a convenience (Monczka et al., 2010). The term may also be used as a verb to mean taking inventory or to count all goods held in inventory. For the purpose of this study, inventory management is defined as managing the parts or stocks of materials in any form inside the organization and stabilizing the flow of materials with respect to the variability in demand.

\subsubsection{Inventory Management Techniques}

\subsubsection{Economic Order Quantity (EOQ) Model}

The economic order quantity, which is also recognized as the Wilson EQQ model, is an inventory management technique that identified the most favorable quantity to order, which is in line with minimizing the total variable expenses that are needed to order as well as to hold inventories (Lee, 2002). Economic Order Quantity denotes the optimal ordering level of an inventory which helps in the minimization of expenses. This inventory management approach (EOQ) makes the assumption that the demand for an item is well-known, the lead time is well-known and constant, that the receipt of an order happens immediately, the discounts of quantity are not computed as part of the model and that inventory's shortages do not happen. The EOQ graphs demonstrate the association between the costs of ordering, the expense of holding inventories and the economic order quantity (Nair, 1995).

\subsubsection{Just in time (J.I.T) Model}

The Just in Time is an inventory management practices with the objective of maintaining just sufficient material at the right place and at the right time in order to make first the right quantities of inventories (Carlson, 2002). This concept was established by manufacturing businesses in Japan in which inventories are acquired only when demanded in a business for the purpose of production and this focused on enhancing the return on investment of a firm through the reduction of in-process inventory and its associated costs (Schonsleben, 2000).In this system, the supplier has the responsibility of delivering the workings and part to the assembly line "Just in Time" to be assembled. Other names for just in time system is Zero stock inventory and production (Lazaridis\&Dimitrios, 2005)For the just in time method to work successfully the quality of the parts must be very high because defective materials could up halt the operations of the assembly line, there must be dependable relationships and smooth co-operation with suppliers, ideally this implies 12that the supplier should be located near to the firm with dependable transportation available (Konke, 2003). Just in time inventory management system helps in reducing inventory costs by avoiding carriages of excess inventories and mishandling of raw materials. According to Kortz (2003), Just in time purchasing recognizes high costs associated with holding high inventory level and as such it has become important in most organizations to order inventory just in time of production so as to cut costs of holding inventory like storage lighting, heating, security, insurance and staffing (Dimitrios, 2008).

\subsubsection{ABC Analysis}

This inventory control approach is based on the doctrine that a small portion of the items might characteristically represent the bulk of the value of money of the total inventory utilized in the process of production, whilst a 
comparative number of items can be from a small fraction of the financial value of stores (Flores\& Clay, 2012)ABC analysis is sound recognized categorization technique as far as the pareto principle is concerned, whose main purpose is for establishing the items that should be prioritized in the management of an inventory (Ramanathan 2006). Flores and Whyback (2007) is of the view that ABC analysis is a method for prioritizing inventories. Inventories are classified into 3 sub-classes, including A, B and C. A large portion of the efforts of management are utilized on administering A ItemsA, B in-between and C items get the least attention.2.3.4 Vendor Managed Inventory (VMI)Management of inventory supply determines the way an organization will propel itself to high performance effectiveness and competence. Many firms have resulted to VMI systems which assist the provider to monitors clientele inventory usage. Through the VMI system customers can avoid stock outs since the supplier will already have replenished the stocks and also there will be no costs related to handling of inventory since the supplier will know the quantity that is needed and which product will be put on the shelves.

\subsubsection{Bar-coding}

Bar-coding is the most popular used method of tracking a product for purposes of understanding the level of inventory, reorder and deliveries or sales; this enables to avoid issues of stock outages or overstocking. Barcoding helps to track a particular item at any specific time. The staffs in the stores along with overseer scan use bar-coding systems to ensure that work orders are linked, and that the purchase orders are thoroughly linked to the level of stock which is replenished, and that all auxiliary parts in addition to equipment are tracked. Once items leave the store, they are instantly recorded in the system thus making it possible to understand which stock is running low and the items to be placed. So as to guarantee that the data processed by the barcode is helpful, the ERP (Enterprise Resource Planning) system, utilized as the pillar for the bar-coding system, has to be precise at the moment of roll-out in order to ensure the data is significant and effortlessly analyzed (Eroglu, Brent and Waller, 2011).

\subsubsection{Simulation}

The uses of simulation in inventory management usually occur for purpose of responding to the wish for a proper decision making process that would take into consideration the complexities and variances within the environment of a system. A majority of simulation researches regarding inventory systems endeavored to establish the most appropriate arrangement for the inventory system in order to attain the predetermined goals. A small number of simulation models were established to address the inventory system optimization. A number of researches used simulation to establish an inventory control approach associated with tracking signals to assess performance. The other established models aimed at special situations of inventory state (Eckert, 2007).Badri (1993) established a simulation based decision-support system for controlling and managing inventory by taking into consideration the impact of changes in demand, the point of reordering, the control of the stock level, period between the reviews, as well as the lead time. Nonetheless, the approach took into consideration just the case of one product inventory model. In this research, the replica established by Badri (1993) was expanded to integrate a generalized multi-product inventory system.

\subsubsection{Material Requirement Planning (MRP)}

MRP is a computer-based inventory management system designed to assist production managers in scheduling and placing orders for dependent demand items. Dependent demand items are components of finished goodssuch as raw materials, component parts, and subassemblies - for which the amount of inventory needed depends on the level of production of the final product. MRP works backward from a production plan for finished goods to develop requirements for components and raw materials. "MRP begins with a schedule for finished goods that is converted into a schedule of requirements for the subassemblies, component parts, and raw materials needed to produce the finished items in the specified time frame. Thus, MRP is designed to answer three questions: what is needed? How much is needed? And when is it needed? (Stevenson, 2009) 2.3.3.Barcode scanner system \& Radio Frequency Identification (RFID) tags Barcode system represents major benefits to supermarkets, discount stores and departmental stores. Barcodes assign special numbers to each and every item you're trying to track, all with an integrated system of data. Upon scanning your inventory's barcodes, they automatically get decoded and entered into a database, which then allows you to track and maintain inventory quantities, pricing, and any other data you want to save. In addition to their increase in speed and accuracy, these systems give managers continuous information on inventories, reduce the need for periodic inventories and order-size determinations (Stevenson, 2009). On the other hand, indicated that, barcode scanning though helps track inventory is not very efficient in tracking manufacturing products and services as they carry only a limited amount of information and require direct line-of-sight to be scanned; Hence, the need to adopt the radio frequency identification system (RFID).

\subsection{Inventory costs}

Inventory represents an investment in the organization whether as a result of deliberate policy or not (Lucey and Lucey, 2002).According to Coyle et al.(2003) inventory costs are important for three major reasons. First, it 
represents a significant component of the total logistics costs in many companies. Second, the inventory levels that a firm maintains in the supply chain affect the level of service the firm can provide to its customers. Third, cost trade-off decisions in logistics frequently depend upon and ultimately affect inventory costs. Basically, four types of inventory costs exist. These include item costs, holding costs, ordering costs, and shortage costs. Some literature also make mention of overstocking costs. Costs associated with inventory are generally categorized as either direct or indirect costs (Coyle et al., 2003).2.1.1.Item costs are simply the costs of the items that are held as inventory. If item are manufactured in-house, this cost is the value of the item at that point in the system, to include all material and direct labor costs. For items that are purchased from outside the firms, this is usually the unit price we pay to our vendor (Coyle et al., 2003).

\subsubsection{Holding or carry costs}

Costs associated with carrying items in inventory. Carrying costs include interest, insurance, taxes, depreciation, obsolescence, deterioration, spoilage, pilferage, breakage, and warehousing costs (heat, light, rent, security). They also include opportunity costs associated with having funds that could be used elsewhere tied up in inventory (Stevenson, 2009).

\subsubsection{Ordering costs}

International Journal of Development and SustainabilityVol.5No.3 (2016): 105-119108ISDS www.isdsnet.com these are costs of ordering and receiving inventory; they are the costs that vary with the actual placement of an order. Beside shipping cost, they include, determining how much is needed, preparing invoices, inspecting goods upon arrival for quality and quantity, and moving goods to temporary storage. Ordering costs are generally expressed as a fixed amount per order regardless of order size (Stevenson, 2009).

\subsubsection{Shortage costs/ stock-out costs}

Shortage costs result when demand exceeds the supply of inventory on hand. These costs can include the opportunity cost of not making a sale, loss of customer goodwill, late charges and similar costs. Furthermore, the cost of lost production or downtime is considered as shortage cost. Such costs can easily run into hundreds of dollars a minute or more. Shortage costs are sometimes difficult to measure and they may be subjectively estimated (Stevenson, 2009).

\section{Research Design and Methodology 3.1 Research Design}

The researcher used descriptive survey research design method. Because it helps to gather data at a particular point in time with intention of describing the nature of existing conditions, or identification standards against which existing conditions can be compared or determining the relationship that exists between specific events. In addition to this, it is used to gather data on a one shot basis and hence is economical and efficient Abdi Zegeye, (2009:29)

\subsection{Target population and Data Sources}

The target populations for this study are from current active Administrative staff of the University. The researcher was used both primary and secondary sources of data. The primary sources of data were collected from questionnaire and interview.

\subsection{Sampling Technique}

To determine the sample the researcher would use purposive sampling technique. This sampling technique would be used because to get the necessary data deliberately from eligible officers who are worked for more than one year and above at their respective offices as inventory management related activities. For this end 60 questions were distributed and interview conducted to the officers.

\subsection{Method of data analysis}

The data were entered by using SPSS version 20.Based on the gathered necessary information from different sources, the researcher able to analyzed data by using descriptive statistics like percentage, tabulation, and statements. The respondents were classified in work places. The under trying reason is that data was collected in quantitative method. This is the most important method of analysis for trade purpose. Hence, for all data interpretation was made relying on the descriptive analysis. Finally was for warded recommendation, findings and conclusion were done accordingly.

\section{DATA PRESENTATION AND ANALYSIS}

The structured questionnaire was distributed to 65 workers and 60 questioners filled and collected. The collected data coded and analyzed by the aid of SPSS Software version 20 . The analysis of the found data is going to be as follows: 
Part I. Background of the respondents' information

Table 4.1: Background of the respondents' information

\begin{tabular}{|llll|} 
No & Item & Respondents & \\
\hline & Sex & No & Percentage \\
\cline { 2 - 4 } & Male & 54 & $\mathbf{9 0}$ \\
\cline { 2 - 4 } & Female & 6 & $\mathbf{1 0}$ \\
\cline { 2 - 4 } & Total & $\mathbf{6 0}$ & $\mathbf{1 0 0}$ \\
\hline 2. & Educational background & No & Percentage \\
\cline { 2 - 4 } & Primary school & 14 & $\mathbf{2 3 . 3}$ \\
\cline { 2 - 4 } & Secondary school & 24 & $\mathbf{4 0}$ \\
\hline certificate & - & $\mathbf{2 0}$ \\
\cline { 2 - 4 } & Diploma & 12 & $\mathbf{1 6 . 7}$ \\
\cline { 2 - 4 } & Degree & 10 & - \\
\hline Master and above & - & $\mathbf{1 0 0}$ \\
\hline \hline Total & $\mathbf{6 0}$ & \\
\hline
\end{tabular}

Source: (Survey result 2019)

As the data shows on the above table the greater number $(90 \%)$ of the respondents are composed male and $(10 \%)$ of the respondents female workers. Again, the greater numbers $(40 \%)$ of the employees are from secondary school.

Part II. Existing Inventory Management Practices

Table: 4.2 Inventory Management Practices

No Item

1. What is the safety and security level of inventories in the store?

\section{Excellent}

\begin{tabular}{lll|}
\hline Very good & 12 & $\mathbf{2 0}$ \\
\hline Good & 20 & $\mathbf{3 3 . 3}$ \\
\hline Average & 6 & $\mathbf{1 0}$ \\
\hline Poor & 22 & $\mathbf{3 6 . 7}$ \\
\hline Total & $\mathbf{6 0}$ & $\mathbf{1 0 0}$ \\
\hline What are the major actions the organizations use to improve the inventory system? & \\
\hline Standardize stock item & 17 & $\mathbf{2 8 . 3}$ \\
\hline Reduce lead time & 25 & $\mathbf{4 1 . 7}$ \\
\hline Reduce cycle time & 4 & $\mathbf{6 . 7}$ \\
\hline User Fewer supplies & 14 & $\mathbf{2 3 . 3}$ \\
\hline \hline Total & $\mathbf{6 0}$ & $\mathbf{1 0 0}$ \\
\hline
\end{tabular}

Source: (Survey result 2019)

As revealed in the above table majority $(36.7 \%)$ of the respondents stated that the level of inventories handling practice is poor. Whereas regarding the major actions the organizations use to improve the inventory system majority of the respondents $(41.7 \%)$ responded that the university uses reduce lead time. 
Part: III. Challenges of inventory Management practices

Table 4.3: Inventory problem the organization always face

\begin{tabular}{|lll|} 
No. & Item & \multicolumn{2}{c|}{ Respondents } \\
1. & $\begin{array}{l}\text { Nhat type of inventory problem the organization always face with source of supply } \\
\text { problem }\end{array}$ & Percentages \\
\hline Repetitive of supply problem & - & - \\
\hline Problem of flexible demand & 42 & $\mathbf{7 0 . 0}$ \\
\hline Problem lead time & 18 & $\mathbf{3 0 . 0}$ \\
\hline Total & $\mathbf{6 0}$ & $\mathbf{1 0 0}$ \\
\hline 2. & 40 & $\mathbf{6 6 . 7}$ \\
\hline Prom the following which is the major inventory cost of your organization? & - \\
\hline Order setup cost & - & $\mathbf{1 6 . 7}$ \\
\hline Holding cost & 10 & $\mathbf{1 6 . 7}$ \\
\hline Stack out cost & 10 \\
\hline \hline Total & $\mathbf{6 0}$ & $\mathbf{1 0 0}$ \\
\hline
\end{tabular}

Source: (Survey result 2019)

Concerning the type of inventory problems of the organization majority $(70 \%)$ of respondent responded problem of flexible demand and (30\%) of respondents responded the problem of lead time from the supplier is the other problem. This indicates that more of the respondents say that the major problem of inventory control of the organization is lack of flexibility on the demand of items. As the above table shows that $(66.6 \%$ of respondents responded purchasing cost is the major cost and for the cost of purchasing the organization is need many construction materials and for office material incur very high cost as we as in the case of distance between the store and their work place the organization is incur high stock out cost.

\section{Table 4.3: The current challenges of inventory management practices of the institution}

\begin{tabular}{|c|c|c|c|}
\hline \multirow[b]{2}{*}{ No } & \multirow[b]{2}{*}{ Item } & \multicolumn{2}{|c|}{ Respondents } \\
\hline & & No & Percentage \\
\hline \multirow[t]{4}{*}{1.} & Does the university store situated near to the user and supplier? & & \\
\hline & Yes & 20 & 33.3 \\
\hline & No & 40 & 66.7 \\
\hline & Total & 60 & 100 \\
\hline \multirow[t]{4}{*}{2.} & Does the organization has computerized way of recording items flow & & \\
\hline & Yes & 21 & 35.0 \\
\hline & No & 39 & 65.0 \\
\hline & Total & 60 & 100 \\
\hline \multirow[t]{4}{*}{3.} & Do you think that there is sufficient staff for the store keeping function & & \\
\hline & Yes & 15 & 25 \\
\hline & No & 45 & 75 \\
\hline & Total & 60 & 100 \\
\hline \multirow[t]{7}{*}{4.} & What type of relation does your institution with its suppliers & & \\
\hline & Excellent & - & - \\
\hline & Very good & - & - \\
\hline & Good & 10 & 16.7 \\
\hline & Average & 16 & 26.6 \\
\hline & Poor & 34 & 56.7 \\
\hline & Total & 60 & 100 \\
\hline \multirow[t]{4}{*}{5.} & Did the existing strategies produce the desired results in your institution? & & \\
\hline & Yes & 22 & 36.7 \\
\hline & No & 38 & 63.3 \\
\hline & Total & 60 & 100 \\
\hline \multirow[t]{4}{*}{6.} & Is you institution has formal way of item removal and maintaining functions? & & \\
\hline & Yes & 15 & 25 \\
\hline & No & 45 & 75 \\
\hline & Total & 60 & 100 \\
\hline
\end{tabular}

Source: (Survey result 2019) 
Regarding the location of the store to the users, majority $(66.7 \%)$ of the respondents stated that the physical location is not suitable to the users and the supplier-university relation is also poor. This indicates there is poor relationship between university to suppliers and also the inside location of stores are not suitable for the day to day functioning. Following this response large number of respondents (75\%) the institution has no qualified and enough man power in the store and ware house operations. Regarding the institution to supplier relationship majority $(56.7 \% 0$ stated that the university has poor relationship to its suppliers. To the concern of existing strategies produce the desired results majority $(63.3 \%)$ stated that which is not strategically effective for the institutional functions

As revealed in the above table majority $(65 \%)$ responded that the university has no formal item recording procedure and which is not computerized. For the case of the institution has formal way of item removal and maintains functions or nothing this case large number $(75 \%)$ stated that the university has no formal way of waste removal services.

\section{SUMMARY, CONCLUSIONS AND RECOMMENDATIONS}

\subsection{Summary and Conclusions}

Based on the study outcome the following major findings are summarized and concluded as follows:

The university has no clear inventory management strategy which would be implemented by the employees. In addition to this the university has face $d$ great problem in item protection and their safety level. The university spent its long time in item reception process which is very long procedural and there is weak relation with the suppliers and that results in high complain with the suppliers. The institution spent its large amount of budget on purchasing cost. The store location is very poor and which is far from main offices and discomforts the day to day function. Moreover, the staff who are involved in the store control areas are not educated in the fields and have no scientific way of control and the have also no computerize ways of recording of its flow. Moreover, the university`s existing inventory managing strategy is not efficient and effective to achieve desired result and also organization functions.

\subsection{Recommendations}

The University is facing the problem of lead time which is late delivery and poor supplier relationship. So It is advisable for the company if it adequate inventory on hand (safety stock) to overcome the problem of late delivery by the suppliers. Classification and codification of the inventories in the store and also store location is not appropriate. Therefore, it is advantageous for the company if use classification and modification inventories should be scientific and system abased. Furthermore, for the better functions and effectiveness of the university, it is better if the university hires qualified staff for store functioning and adopting computerized way of recording items in the store and outside the store. Moreover it is preferable for the university is it develops and follows waste items disposal and re-use and uphold procedures.

\section{REFERENCES}

1. Andel, Tom, and Daniel A. Kind. "Flow It, Don't Stow It." Transportation and Distribution, May 1996.

2. Bergin, Sarah. "Make Your Warehouse Deliver: New Developments in Warehouse Management Systems Inspire New Productivity in Needy Operations." Transportation and Distribution, February 1997.

3. Ballou.R.H. (1992). Business Logistics management, $4^{\text {th }}$ edition. Englowoo Cliffisi London; Prentice Hall.

4. Betts, Mitch. "Manage My Inventory or Else!" Computer-world, 31 January 1994.

5. Camacho, E. F. and Bordons, C., 2002, Model Predictive Control. Springer-Verlag London Limited Google Scholar

6. Eskow, Dennis. "Rising Stock: Integrated Inventory Systems Help Companies Shoot Economic Rapids." PC Week, 5 June 1995.

7. Fianko A et al, (2016) Assessing the inventory management practices in a selected company in Ghana. IJDS14122701.

8. Hennet, J.-C., 2003. A bimodal scheme for multi-stage production and inventory control. In Automatica, Vol 39, pp. 793-805. CrossRefzbMATHMathSciNetGoogle Scholar

9. https://www.referenceforbusiness.com/encyclopedia/Int-Jun/Inventory-ControlSystems.html\#ixzz5icNct6fC

10. Koivisto, H., Kimpimäki, P., Koivo, H., 1991. Neural predictive control - a case study. In 1991 IEEE International Symposium on Intelligent Control.IEEE Press. Google Scholar

11. Lambert, E. P., 1987. Process Control Applications of Long-Range Prediction. PhD Thesis, University of Oxford. Trinity. Google Scholar

12. Maciejowski, J. M., 2002, Predictive Control with Constraints. Pearson Education Limited Google Scholar

13. Pachura, Ronald. "When Is Enough, Enough? Inventory Control Contributes Directly to a Company's Profitability." IIE Solutions, October 1998. 
14. Philip, Kotler, (1999). Marketing Management; Analysis Planning Implementation and Control, $9^{\text {th }}$ edition. Prentice Hall New Delhi.

15. Rivera, D. E., Braun, M. W., Flores, M. E., Carlyle, W. M., Kempf, K. G., 2003. A Model predictive control framework for robust management of multi-product, multi-echelon demand networks. In Annual Reviews in Control, Vol. 27, pp. 229-245. CrossRefGoogle Scholar

16. Towill, D. R., 1996. Industrial dynamics modeling of supply chains. In International Journal of Physical Distribution \& Logistics Management, Vol. 26, No. 2, pp.23-42. CrossRefGoogle Scholar

17. Udo, Godwin J. "The Impact of Telecommunications on Inventory Management." Production and Inventory Management Journal, spring 1993.

18. Tzafestas, S., Kapsiotis, G., Kyriannakis, E., 1997. Modelbased predictive control for generalized production problems. In Computers in Industry, Vol. 34, pp. 201-210. CrossRefGoogle Scholar

19. Weisfeld, Barry. "Automated Ordering Puts Profits in Sight." Transportation and Distribution, February 1997.

20. Ydstie, B. E., Grossmann, I. E., Perea-López, E., 2003, A Model predictive control strategy for supply chain optimization. In Computers and Chemical Engineering, Vol. 27, pp. 1202-1218. Google Scholar 